Article

\title{
Influence of Phenylmethylsilicone Oil on Anti-Fouling and Drag-Reduction Performance of Silicone Composite Coatings
}

\author{
Qiang Yang, Zhanping Zhang *, Yuhong Qi and Hongyang Zhang \\ Department of Materials Science and Engineering, Dalian Maritime University, Dalian 116026, China; \\ 1120180341yq@dlmu.edu.cn (Q.Y.); yuhong_qi@dlmu.edu.cn (Y.Q.); zhy686@dlmu.edu.cn (H.Z.) \\ * Correspondence: zzp@dlmu.edu.cn; Tel.: +86-411-8472-3556
}

Received: 22 November 2020; Accepted: 16 December 2020; Published: 17 December 2020

check for updates

\begin{abstract}
In this study, we explore the effect of phenylmethylsilicone oil (PSO) addition amount and viscosity in a fouling release coating based on polydimethylsiloxane (PDMS). The surface properties, mechanical properties, anti-fouling and drag-reduction performance of the coating were studied. Meanwhile the influence of the basic properties of the coating on the anti-fouling and drag-reduction performance was also studied. Subsequently, the antifouling performance of the coating was investigated by the Navicula Tenera and bacteria adhesion test. As a result, the high content of PSO paint has a high foul removal rate. The incorporation of PSO into paint can reduce the elastic modulus and surface energy of the coating to reduce its relative adhesion factor (RAF). The lower the RAF, the better the antifouling effect of the coating. The drag-reduction performance of the coating was verified by the torque selection experiment, and the results showed that incorporation of PSO into paint can enhance the elongation and hydrophobicity of the coating, thereby increasing the drag reduction rate of the coating.
\end{abstract}

Keywords: polydimethylsiloxane; phenylmethylsilicone oil; anti-fouling; drag-reduction; viscosity; additive amount

\section{Introduction}

In recent years, the concept of energy saving and emission reduction has gradually attracted people's attention. In the shipping industry, the most efficient way to save energy is to reduce the forward drag of ships [1]. While the ship is moving forward, not only the seawater drag, but also the adhesion of marine fouling organisms like diatoms and bacteria, they both accelerate biological corrosion and increases surface roughness [2-5].

Polydimethylsiloxane (PDMS), an elastomer, has low surface energy and roughness, which reduces the adhesion between it and marine organism [6-8]. Unfortunately, the PDMS has a high interfacial energy with water, it is beneficial to adhesion bacteria and sludge, and limits the use of the organic silicon coating under static conditions [9]. Moreover, PDMS is hard to apply under dynamic conditions, because it is difficult to inhibit the adhesion of diatoms. Even if the ship speed is as high as 30 knots, the diatoms may still adhere firmly to the coating surface [10].

At present, a large number of studies have shown that modifying the performance of silicone coating can improve its anti-fouling and drag reduction effect to a certain extent. Common modification methods include building a super-hydrophobic surface [11-13], biomimetics [14], adding functional additives [15] and so on. Super-hydrophobic coatings and biomimetic coating have good anti-fouling and drag-reducing effects, but the manufacture of the materials is complicated and the surface structure is unstable, which have great limitations in practical use. Adding functional additives to the coating can effectively improve the performance of the coating, and the operation is simple and efficient [16]. 
As a kind of functional additive, silicone oil has attracted wide attention for its hydrophobicity, lubricity and other characteristics [17]. Amini et al. [18] injected silicone oil into PDMS to manufacture silicone oil modified silicone coating, studied the coating performance by simulating the marine environment, and found that the addition of silicone oil can significantly reduce the protein secretion and adhesion of mussels. Gui et al. [19] injected silicone oil into the self-assembled nano-scale coating and found that when the content of silicone oil is $20 \mathrm{wt} . \%$, its ice-removing ability exceeds that of superhydrophobic surfaces. Ba et al. [20] prepared PSO and silicone blend film by a two-step method, explored the effect of the viscosity of PSO on silicone oil precipitation time, and found that the increase in viscosity can reduce the precipitation time of silicone oil. Galhenage [21] designed silicone oil-modified siloxane-polyurethane coating and found that the modified coating significantly improve the antifouling performance. The modified coating still has high hydrophobicity after soaking for a long time.

So far, people have mainly studied the surface properties and protein adhesion of silicone oil-modified silicone coatings, but the adhesion and drag reduction properties of diatoms have not been researched in depth. In this paper, phenyl silicone oils of different molecular weights were added to the silicone coating by means of mechanical stirring. To study the drag reduction performance of silicone coating diatoms, the water contact angle, surface energy and elastic modulus of PSO were measured. The experimental results show that when the addition amount of low molecular weight PSO (30 mPa.s) is more than 5\%, the organic silicon coating has less Navicula Tenera attachment and higher drag reduction rate.

\section{Materials and Methods}

\subsection{Experimental Materials and Equipment}

Hydroxyl-terminated polydimethylsiloxane (PDMS, 31900-57-9) with the viscosity of 10,000 mPa.s was purchased from Dayi Chemical Industry Co. Ltd. (Yantai, China). Phenylmethylsilicone oil (PSO, 63148-58-3) with the viscosities of 30, 75 and $100 \mathrm{mPa} \cdot \mathrm{s}$ was obtained from Dayi Chemical Industry (Yantai, China). Tetraethylorthosilicate (TEOS, 68412-37-3), Dibutyltin dilaurate (DBTDL, 77-58-7) was obtained from Kemiou Chemical Reagent Co. Ltd. (Tianjin, China) as analytical grade. Navicula Tenera was bought from Qingdao Chinese Academy of Sciences Seaweed Germplasm Bank (Qingdao, China).

\subsection{Preparation of the Composite Coating}

\subsubsection{Preparation of Silicone Topcoat}

The topcoat consists of three components:

1. Component A: It is composed of Polydimethylsiloxane (PDMS), phenylmethylsilicone oil (PSO) and powder according to the formula ratio. The specific ratio is shown in Table 1.

2. Component B: curing agent, mixed with xylene and TEOS in a mass ratio of 7:3.

3. Component $C$ : catalyst, mixed with xylene and DBTDL in a mass ratio of $7: 3$.

Table 1. Formulation of coating component A.

\begin{tabular}{cccccccc}
\hline Sample & W-0 & B30-3 & B30-5 & B30-7 & B30-9 & B75-9 & B100-9 \\
\hline PDMS (g) & 100.00 & 100.00 & 100.00 & 100.00 & 100.00 & 100.00 & 100.00 \\
Additives (g) & 9.00 & 9.00 & 9.00 & 9.00 & 9.00 & 9.00 & 9.00 \\
Pigments (g) & 36.00 & 36.00 & 36.00 & 36.00 & 36.00 & 36.00 & 36.00 \\
PSO (g) & 0.00 & 4.48 & 7.63 & 10.91 & 14.34 & 14.34 & 14.34 \\
\hline
\end{tabular}

PSO is the only variable. Mix PDMS, PSO, pigments, and additives according to the formula ratio, and used a BGD 750 Versatile Sand-Milling Dispersion-agitator (Guangzhou Biuged Laboratory Instrument Supplies Co, Ltd., Guangzhou, China) at 4500 rpm blend for $30 \mathrm{~min}$. After that, pour the 
mixed liquid into a tinplate container for use as the paint component $\mathrm{A}$. The specific process is shown in Figure 1. Mix the three components A, B, and C at 25:4:1. According to different painting requirements, a certain amount of xylene can be added to adjust the coating viscosity.

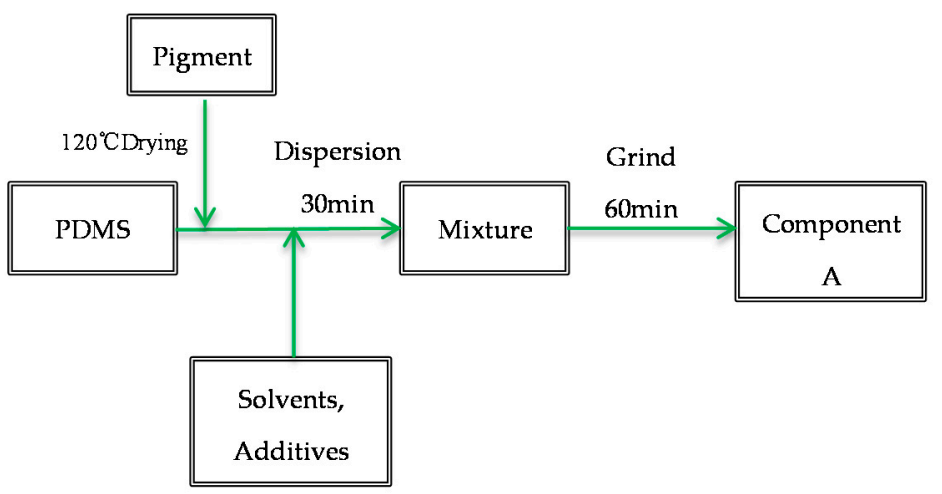

Figure 1. Preparation process of component A of silicone topcoat.

For testing the surface property and antifouling property of the silicone topcoat, the paint was sprayed on glass slides with a dimension of $75 \mathrm{~mm} \times 25 \mathrm{~mm} \times 1 \mathrm{~mm}$. In order to study the mechanical properties of the silicone topcoat, it was poured into a Teflon mold with a dimension of $150 \mathrm{~mm} \times 150 \mathrm{~mm} \times 2 \mathrm{~mm}$.

According to the addition amount and viscosity of PSO to mark, which is shown in Table 1, the " $X$ " in BX-Y represents the viscosity of PSO. The viscosity of PSO is 30, 75 and $100 \mathrm{mPa} \cdot \mathrm{s}$. The " $Y$ " in BX-Y represents the ratio of the mass of PSO and component A, multiplied by 100 .

\subsubsection{Preparation of Composite Coating}

We chose WS T-207 epoxy strontium yellow paint (P4) as the primer, and WS T-208 SM epoxy paint (HT1) as the intermediate paint. P4, HT1 was obtained from the 53rd Research Institute of China North Industries Group (Jinan, China). The silicone connecting paint was prepared by Liu [22]. The preparation method of the silicone topcoat is shown in Section 2.2.1. The spraying process is shown in Figure 2.

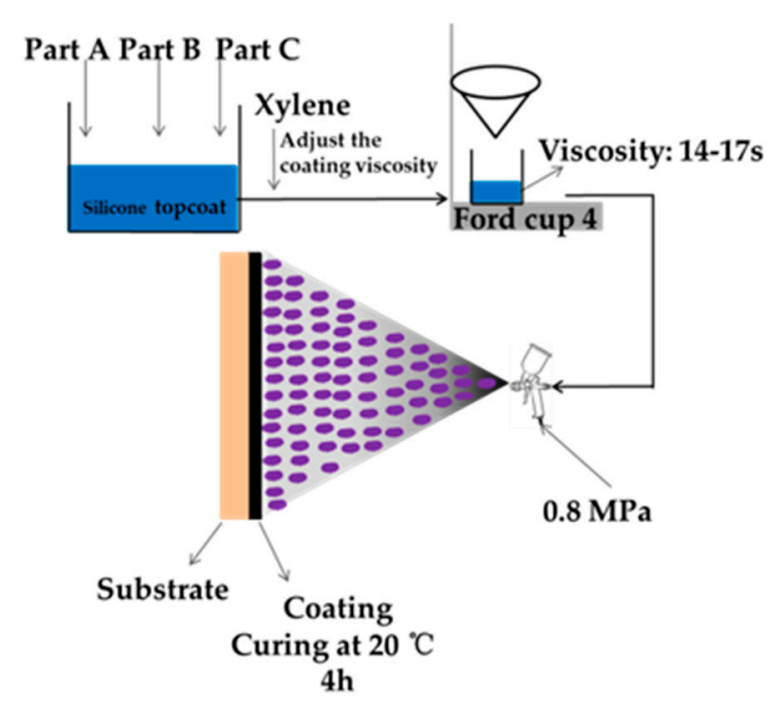

Figure 2. Spraying process of silicone topcoat.

The specific coating distribution of the composite coating is shown in Figure 3. The thickness of epoxy primer, epoxy intermediate paint, silicone connecting paint and silicone topcoat were 80-120, 
80-100, 50-70 and 150-200 $\mu \mathrm{m}$, respectively. In order to study drag-reduction of composite coating, the paint was sprayed on the glass disc.

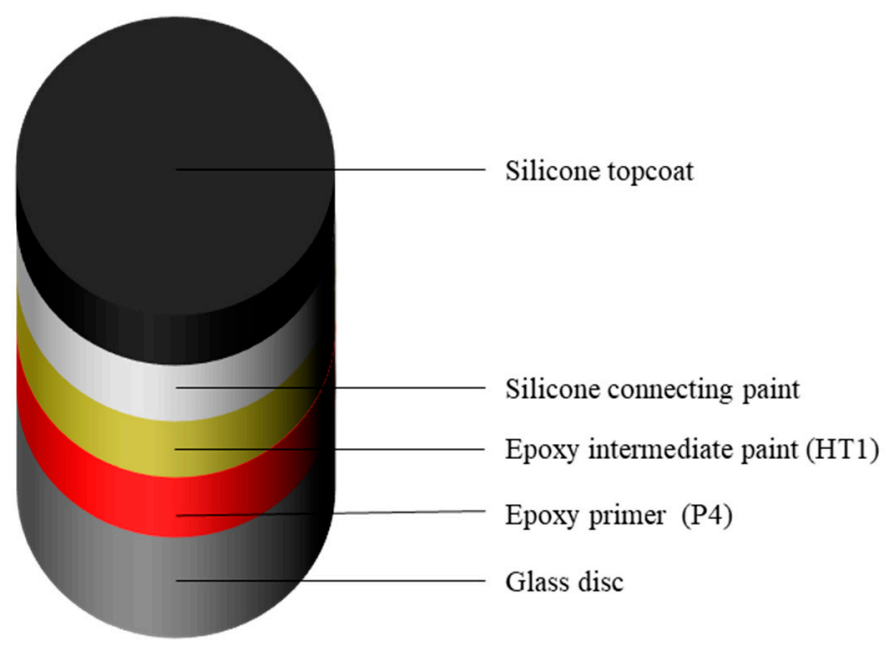

Figure 3. The spraying sequence of composite coatings.

\subsection{Experiment and Characterization}

\subsubsection{Contact Angle Test}

The JC2000 contact angle measuring instrument (Shanghai Zhongchen Digital Technic Apparatus Co., Ltd., Shanghai, China) is used to measure the water contact angle and diiodomethane contact angle of the coating. Pick three points randomly on the coating and take the average value. The size of the detection liquid is $3 \mu \mathrm{L}$, and the image is frozen and recorded after the liquid contacts the sample surface for $3 \mathrm{~s}$. According to the Owens two-liquid method [23], surface free energy of the sample has been calculated.

\subsubsection{Tensile Performance Test}

According to the national standard GB/T 528-2009 (IS037-2005), the coating was cut into $4 \mathrm{~mm} \times 45 \mathrm{~mm}$ dumbbell-shaped tensile specimen. The UTM5105 computer-controlled electronic universal testing machine (Jinan Wance Electrical Equipment Co., Ltd., Jinan, China) was used to perform the tensile properties of the coating sample, and the tensile rate was $50 \mathrm{~mm} / \mathrm{min}$. We selected the tensile data with a strain not exceeding $0.01 \mathrm{~mm} / \mathrm{mm}$ to figure, and obtained the corresponding curve slope after linear fitting, which is the elastic modulus of the tensile specimen.

\subsubsection{Morphology Analysis}

Morphology of the silicone topcoat surface and fractures were measured with the Olympus OLS4000 CLSM (OLYMPUS (China) Co., Ltd., Beijing, China). The line roughness (Ra) of the coating was measured using LEXT analysis software (version 2.2.4).

\subsubsection{Bacteria Removal Ability}

The antifouling performance of the silicone coating was characterized by bacterial adhesion. The test bacteria were selected from the natural seawater of Dalian Yellow Sea. We took 6 samples for each formula, three of which were marked as $\mathrm{P}$ and the other was marked as $\mathrm{Q}$. We placed the samples in fresh natural seawater and soaked them for $24 \mathrm{~h}$. After the soaking was completed, they were rinsed with $P$, washed with $Q$, and we brushed the bacteria into the sterilized seawater with a cotton swab to make a bacterial suspension. Sterilized seawater was used to dilute the bacteria suspension to a volume of $10^{-6}$. Take $10 \mu \mathrm{L}$ from it, inoculate it on $2216 \mathrm{E}$ solid medium, and spread evenly. We took 
pictures to record the experimental results. We used IMAGE PRO PLUS software (version 6.0) to observe the amount of bacteria attached to the surface of the solid medium [24]. The formula of $2216 \mathrm{E}$ solid medium can be found in paper [25].

\subsubsection{Navicula Tenera Attachment Test}

For each formula, we took 6 coated slide samples that had cured for more than 7 days, and placed them in a $2000 \mathrm{~mL}$ beaker. We added $500 \mathrm{~mL}$ sterile seawater and $50 \mathrm{~mL}$ boat-shaped Navicula Tenera liquid in a beaker. We placed it in an HPG-280BX light incubator (Harbin Donglian Electronic Technic Co., Ltd., Harbin, China), with a temperature of $(18 \pm 1){ }^{\circ} \mathrm{C}$, and ratio of light to dark of $12 \mathrm{~h}: 12 \mathrm{~h}$. We took photos to record the adhesion of diatoms in the beaker regularly. Then we took the sample out after 2 days, washed part of them i and rinsed another part. The evaluation method of Navicula Tenera adhesion can be found in paper [26].

\subsubsection{Drag Reduction Test}

According to the national standard GB/T 7791-2014 drag reduction was tested [27]. We fixed the coating sample on the rotating shaft and placed the shaft in the cylindrical experimental water tank (height $0.62 \mathrm{~m}$, radius $0.3 \mathrm{~m}$ ). The water tank was equipped with $175 \mathrm{~L}$ of natural seawater to ensure that the height of the seawater on the upper surface of the sample was greater than $0.3 \mathrm{~m}$ to generate swirl during the rotation. Before and after the test, we ensured that the position of the seawater in the tank and the position of the rotating shaft remained unchanged.

The rotation speed and simulated speed of ship are shown in Table 2 . We tested the speeds over two hours, and recorded the data for $10 \mathrm{~s}$. Then we took the average of the data in the last hour.

Table 2. The corresponding simulated speed of the disc at different speeds.

\begin{tabular}{ccccccc}
\hline Rotating Speed (rpm) & $\mathbf{8 0 0}$ & $\mathbf{1 0 0 0}$ & $\mathbf{1 2 0 0}$ & $\mathbf{1 4 0 0}$ & $\mathbf{1 6 0 0}$ & $\mathbf{1 8 0 0}$ \\
\hline Simulated speed of ship (kn) & 8.14 & 10.18 & 12.21 & 14.25 & 16.28 & 18.32 \\
\hline
\end{tabular}

\section{Results}

\subsection{Surface Properties}

\subsubsection{Roughness}

The surface roughness of the coating is the primary parameter which affects most of the paint's functional properties. The required coating was prepared by spraying technics. The roughness of the coating was tested by Olympus OLS4000 CLSM (field of view area of $1024 \mu \mathrm{m} \times 1024 \mu \mathrm{m}$ ), and the specific results are shown in Table 3.

Table 3. Surface roughness of coating.

\begin{tabular}{cccccccc}
\hline Coating & W-0 & B30-3 & B30-5 & B30-7 & B30-9 & B75-9 & B100-9 \\
\hline Roughness $(\mu \mathrm{m})$ & $0.42 \pm 0.26$ & $0.49 \pm 0.32$ & $0.53 \pm 0.05$ & $0.59 \pm 0.21$ & $0.43 \pm 0.17$ & $0.51 \pm 0.32$ & $0.43 \pm 0.22$ \\
\hline
\end{tabular}

It is found that the initial roughness of all coatings is approximately the same. Roughness will not be used as a variable to affect other properties of the coating.

\subsubsection{Surface Energy}

The influence of the addition amount of PSO (30 mPa.s) on the water contact angle (WCA) is shown in Figure 4a. The results show that the incorporation of PSO can improve the hydrophobicity of the coating to a certain extent. In terms of the functional groups, the hydrophobicity of phenyl groups is better than that of methyl groups. Therefore, the more phenyl groups in the coating, the stronger the 
coating hydrophobicity. When the amount of PSO is the same (Figure 4b), the increase of viscosity will reduce the hydrophobic effect of PSO.

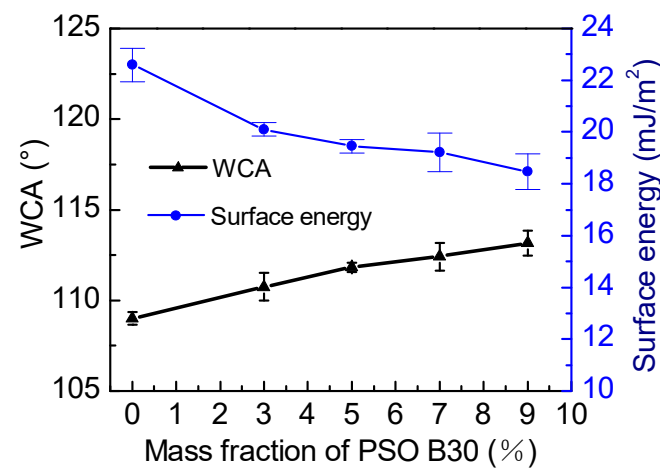

(a)

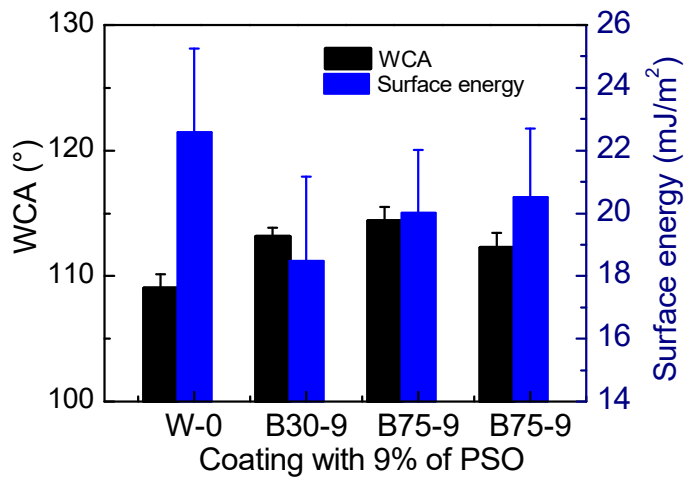

(b)

Figure 4. (a) The effect of PSO addition amount on water contact angle (WCA) and surface energy of silicone topcoat, (b) the effect of PSO viscosity on WCA and surface energy of silicone topcoat.

According to the Owens two-liquid method, we calculated the surface energy of the coating [23]. In Figure 4, with the increase of PSO content, the surface energy of the coating gradually decreases. Because the surface energy of PSO is lower than that of PDMS. According to related studies, the surface energy of PSO (7-100 mPa.s) is about 22.2 to $24 \mathrm{~mJ} / \mathrm{m}^{2}$ [28], so low-viscosity PSO can significantly reduce the surface energy of the coating, which is consistent with the results presented in this article.

\subsection{Mechanical Properties}

The influence of the addition amount and viscosity of PSO on the tensile properties of the silicone topcoat is shown in Table 4, Figure 5.

Table 4. Mechanical properties of coating.

\begin{tabular}{cccc}
\hline Coating & Elastic Modulus (MPa) & Fracture Elongation (\%) & Breaking Strength (MPa) \\
\hline W-0 & $2.44 \pm 0.16$ & $191.54 \pm 2.26$ & $0.46 \pm 0.03$ \\
B30-3 & $1.88 \pm 0.67$ & $210.68 \pm 3.82$ & $0.56 \pm 0.03$ \\
B30-5 & $1.81 \pm 0.56$ & $222.00 \pm 1.45$ & $0.59 \pm 0.06$ \\
B30-7 & $1.82 \pm 0.03$ & $226.84 \pm 4.83$ & $0.80 \pm 0.08$ \\
B30-9 & $1.79 \pm 0.46$ & $251.34 \pm 3.20$ & $0.69 \pm 0.05$ \\
B75-9 & $2.10 \pm 0.26$ & $208.02 \pm 3.36$ & $0.59 \pm 0.05$ \\
B100-9 & $1.73 \pm 0.19$ & $293.60 \pm 2.26$ & $0.81 \pm 0.08$ \\
\hline
\end{tabular}

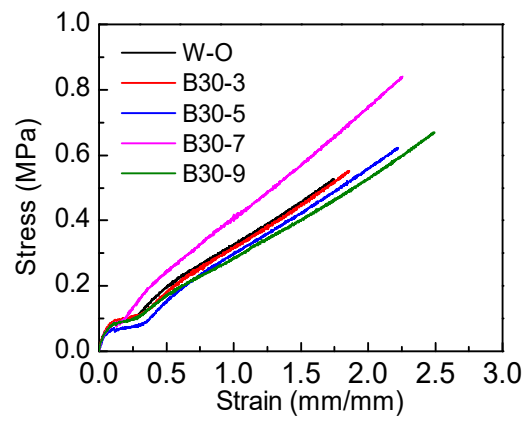

(a)

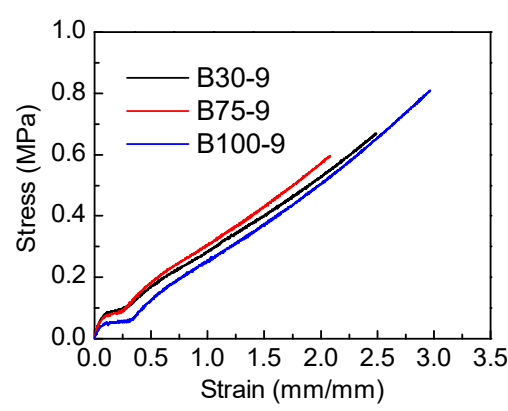

(b)

Figure 5. (a) The effect of PSO addition amount on stress-strain curve of the silicone topcoat, (b) the effect of PSO viscosity on stress-strain curve of the silicone topcoat. 
It can be seen from Table 4 and Figure 5 that the incorporation of PSO will decrease the elastic modulus of the coating. Because of the non-reactiveness of PSO, being stored in the gaps of molecular chains would reduce the crosslink density of the coating [20]. With the decrease of crosslink density, the mechanical properties of the coating decrease as well. The molecular weight of PDMS is much larger than that of PSO, so the viscosity of PSO has little effect on the stretching curve.

\subsection{Antifouling Performance}

In the ocean, biofouling is a dynamic process that can be divided into three stages: (1) Formation of a nutrient film, (2) Bacteria and diatoms attach to the nutrient film to form a biofilm, (3) Large plankton attach. According to research, the existence of biofilm is conducive to the attachment of large plankton, which provides a foothold and food for large plankton [29]. The study of the anti-adhesion properties of the coating to bacteria and Navicula Tenera is an important means to explore the antifouling properties.

\subsubsection{Bacteria Attachment Performance}

A bacteria attachment test was used to verify the antifouling performance of the coating. With the addition amount and viscosity of PSO as variables, different silicone topcoat samples were made. The images of original bacterial colonies are shown in Figure 6 (different PSO addition amount). The number of bacterial colonies and the removal rate of fouling in each medium are shown in Table 5 . $\mathrm{CFU}$ is the abbreviation of Colony-forming units.

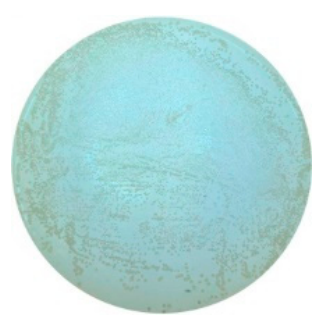

HT1 Rinsed

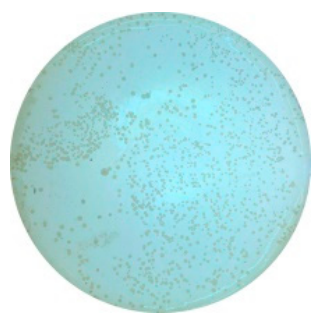

HT1 Washed

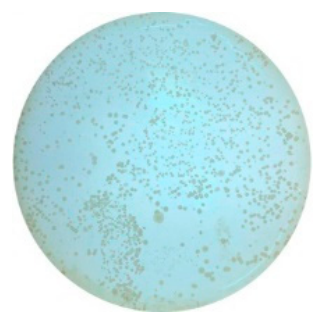

W-0 Rinsed

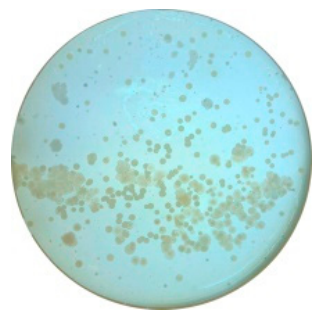

W-0 Washed

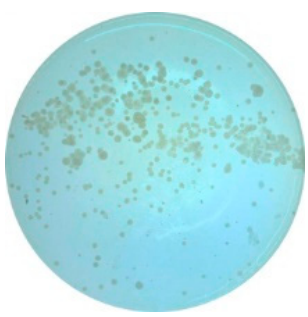

B30-5 Rinsed

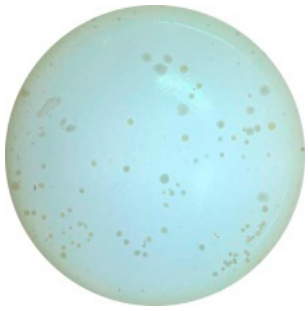

B30-5 Washed

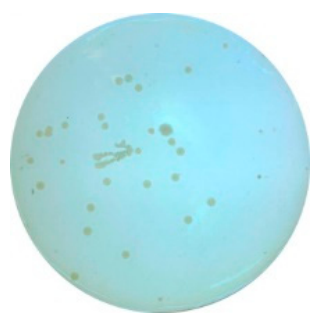

B30-9 Rinsed

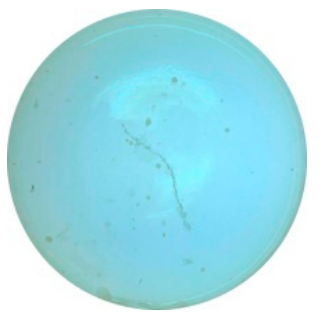

B30-9 Washed

Figure 6. Image of bacterial colonies (different amounts of PSO added).

Table 5. Amounts of colonies and fouling removal rate.

\begin{tabular}{cccc}
\hline \multirow{2}{*}{ Coating } & \multicolumn{2}{c}{ Colony Concentration $\left(\times \mathbf{1 0}^{\mathbf{6}} \mathbf{C F U} / \mathbf{m L}\right)$} & \multirow{2}{*}{ Removal Rate (\%) } \\
\cline { 2 - 3 } & \multicolumn{1}{c}{ Rinsed } & Washed & 4.47 \\
& $760 \pm 2.63$ & $730 \pm 2.50$ & 17.74 \\
HTI & $330 \pm 3.39$ & $270 \pm 3.42$ & 21.56 \\
W-0 & $326 \pm 4.36$ & $253 \pm 5.89$ & 42.42 \\
B30-3 & $170 \pm 3.64$ & $95 \pm 3.57$ & 45.23 \\
B30-5 & $85 \pm 559$ & $47 \pm 5.46$ & 55.56 \\
B30-7 & $36 \pm 1.50$ & $16 \pm 1.91$ & 39.72 \\
B30-9 & $73 \pm 2.30$ & $44 \pm 1.96$ & 40.18 \\
B75-9 & $126 \pm 1.26$ & $75 \pm 2.52$ & \\
B100-9 & &
\end{tabular}


Figure 6 shows that under the same washing conditions, the silicone coating had significantly less colonies than the HT1 coating, which is related to the low surface energy. Due to the fact that surface energy is low [7], bacteria do not easily adhere or adhere unsteadily.

Under the same flushing conditions, as the addition amount of PSO increases, the number of bacteria attached to the coating will gradually decrease. When the addition amount of PSO is constant, compared to the rinsed sample, the washed sample has less bacterial adhesion. This is related to the hydrophobicity of PDMS. Studies have shown that for fouling release coatings, the wider the water contact angle, the stronger the self-cleaning ability of the coating [29].

In Table 5, under the same flushing conditions, as the viscosity increases, the amounts of bacterial colonies of coating gradually increase. This is because the increase of PSO viscosity cannot significantly lead to growth of the hydrophobicity of the coating, which is shown in Figure $4 \mathrm{~b}$. The antifouling effect of the coating, and the bacteria removal rate increases from $17.74 \%$ to $55.56 \%$.

\subsubsection{Navicula Tenera Attachment Performance}

This experiment studied the effect of PSO incorporating the silicone topcoat on Navicula Tenera. The experimental variables are the viscosity and addition amount of PSO. Use WS T-208 SM epoxy paint (HT1) as a contrast coating. We used an ultraviolet-visible spectrophotometer (Labtech UV-2000, Labtech Co., Ltd., Beijing, China) to measure the chlorophyll-a in the coating; the more chlorophyll-a, the more Navicula Tenera attached to the coating surface. The specific results are shown in Figure 7.

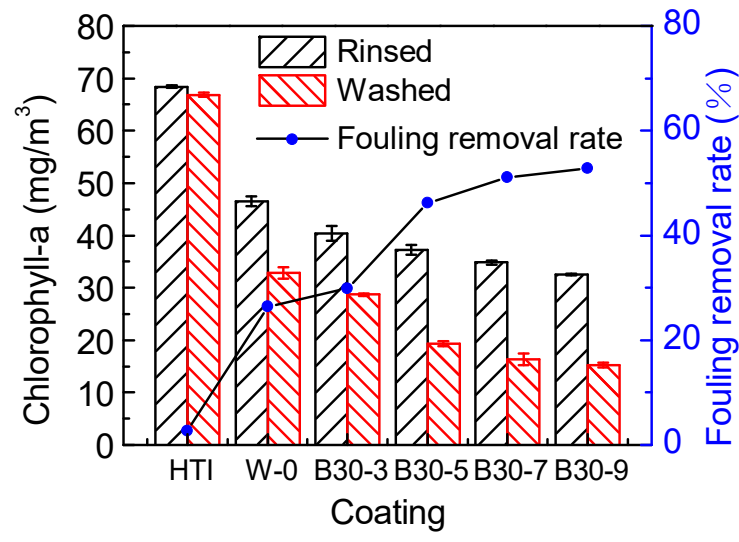

(a)

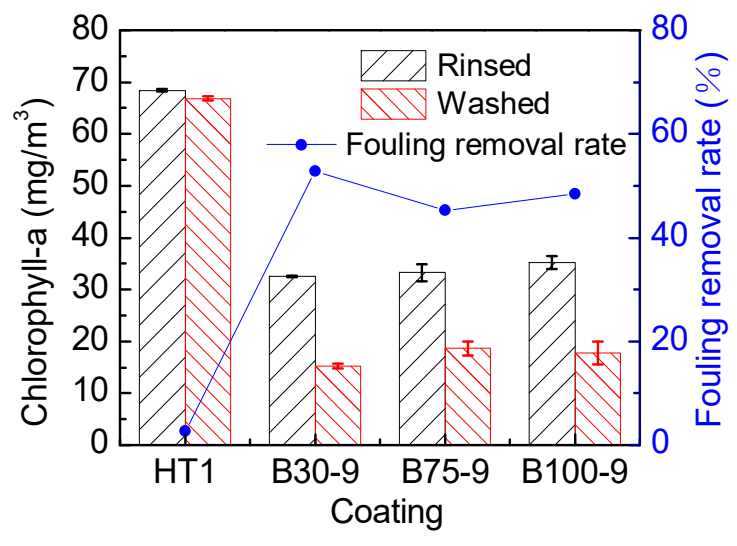

(b)

Figure 7. The influence of the addition amount (a) and viscosity (b) of PSO on the adhesion of Navicula Tenera.

It can be seen from Figure 7 that, compared with epoxy coating HT1, less Navicula Tenera attached to the silicone coating, which is related to the low surface energy of silicone resin [8]. With the increase of PSO addition amount, the removal rate gradually increases. Because the increase of PSO addition amount will reduce the surface energy (Figure 4a) and elastic modulus (Table 4) of the coating, the low elastic modulus could reduce the force to remove fouling organisms from fouling release coatings [30], and high hydrophobicity can inhibit the adhesion of fouling organisms [31], which are the factors that enhance the antifouling properties of the coating.

According to Figure 7b, when the addition amount of PSO is constant, the change of viscosity cannot significantly reduce the adhesion of Navicula Tenera because the change of viscosity cannot reduce the surface energy and elastic modulus of the coating. 


\subsection{Drag Reduction Performance}

The influence of PSO (30 mPa.s) content on drag reduction rate (DR) of coatings is shown in Figure 8. Epoxy paint $H T 1$ was chosen as the comparative coating. This is the drag reduction rate Formula (1).

$$
\mathrm{DR}=\frac{\left(T_{H T 1}-T_{B X-Y}\right)}{T_{H T 1}} \times 100 \%
$$

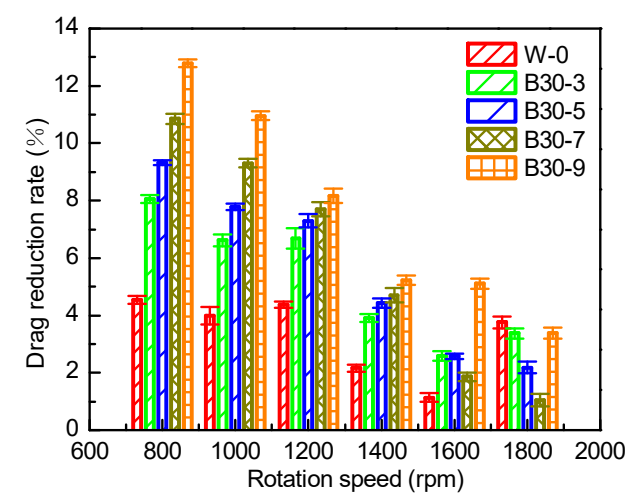

(a)

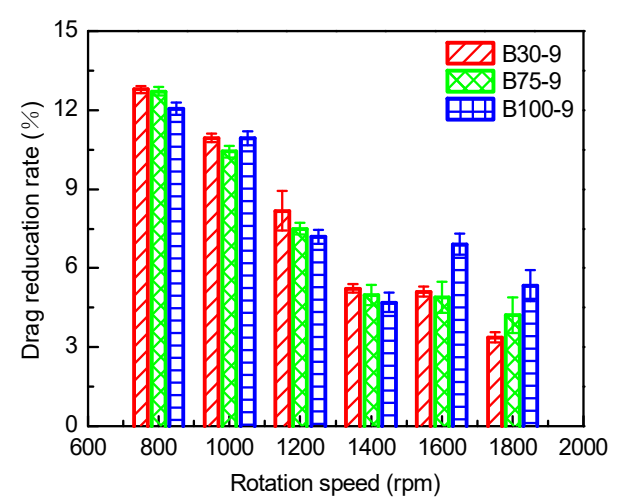

(b)

Figure 8. The influence of the additive (a) and viscosity (b) of PSO on drag reduction rate.

According to Figure $8 \mathrm{a}$, at the speed of $800-1400 \mathrm{rpm}$, as the addition amount of PSO increases, the drag reduction rate of the coating gradually increases because the increase of the PSO addition amount could enhance the hydrophobicity and reduce the elastic modulus. For organic coatings, high hydrophobicity can shrink the solid-liquid connected surface and slow down seawater turbulence [32]. Flexible materials have obvious drag-reduction effects, because of the low elastic modulus of the flexible material, and the surface is easy to deform when subjected to frictional resistance which can be released and play a buffering role [12]. At the speed of 1600-1800 rpm, with the increase of PSO addition amount, the increasing trend of the drag reduction rate is not obvious. Even under some conditions, as the addition amount of PSO increases, the drag reduction rate decreases.

As shown in Figure 8b, the increase in PSO viscosity will not increase the drag reduction rate of the coating, because when the addition amount of PSO is constant, the change in viscosity will not have a major impact on the surface properties and elastic modulus of the coating.

\subsection{Stability in Seawater}

We selected W-0, B30-9 and B75-9 coatings for the seawater immersion experiment, and set the immersion time to $0,3,7,15$ days. We measured the contact angle and surface roughness before and after immersion.

In Figure 9 a, as the immersion time increases, WCA gradually decreases. With the same immersion time, the coating which has more PSO content, WCA decreases more slowly. When the silicone coating is immersed in seawater, the surface of the coating will rearrange under the thermodynamic drive [33], resulting in the decrease of static water contact angle. Adding PSO to PDMS will form a more stable coating, and the cross-linking of silicone oil can make the coating have suitable interface energy [21], thereby reducing the decrease in static contact angle. 


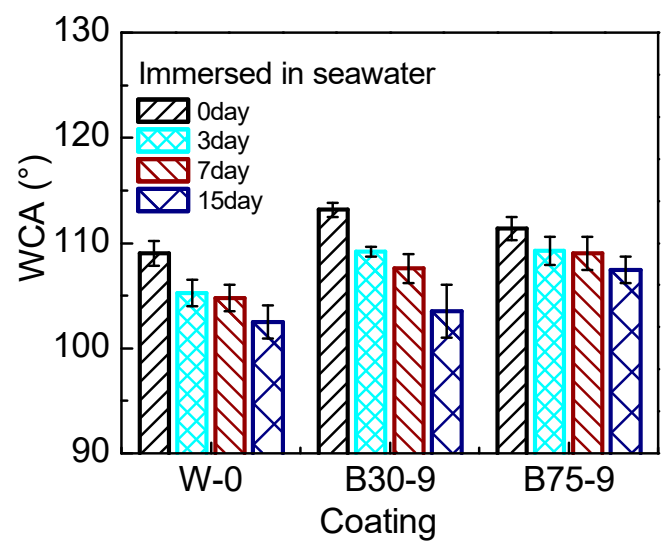

(a)

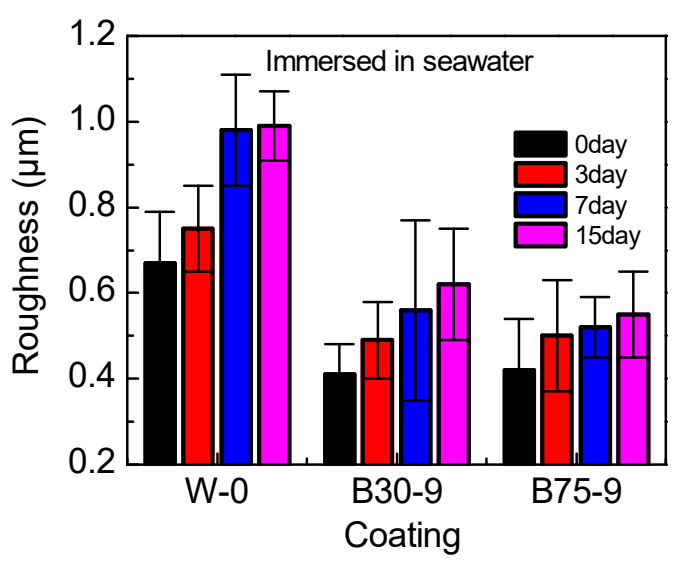

(b)

Figure 9. The relationship between immersion time and WCA (a), roughness (b).

In Figure 9b, the longer the immersion time, the rougher the coating surface. After being immersed for 7 days, the surface line roughness of W-0, B30-9 and B75-9 coatings has been increased to 1.46, 1.36 and 1.23 times, respectively. When the coating was immersed in seawater, with the movement of the molecular chains or the polarity of the seawater, the micro-nano powders originally evenly distributed will agglomerate, resulting in an increase in surface roughness.

\section{Discussion}

\subsection{Effect of Relative Adhesion Factor (RAF)}

Brady proposed the concept of relative adhesion factor (RAF) [34], with RAF $=\sqrt{\mathrm{E} \cdot \gamma}$, where $\mathrm{E}$ is the surface energy of the coating, and $\gamma$ is the elastic modulus of the coating. RAF is an important parameter to characterize the performance of silicone coatings. Brady pointed out that the amount of coating surface marine fouling organisms directly influences RAF. According to Figure 10, with the addition amount of PSO increasing, the RAF decreases and the removal rate is increasing gradually. The experiment proves that RAF is inversely proportional to the fouling removal rate, which in Brady's theory is consistent. Relative adhesion factors can be used to explain the adhesion of bacteria and Navicula Tenera. PSO-modified silicone coating improves the antifouling performance of the coating by reducing the RAF. After modification, the removal rate of bacteria increased from $17.74 \%$ to $55.56 \%$, and the removal rate of primer diatoms increased from $22.46 \%$ to $52.79 \%$. Therefore, PSO enhances the antifouling performance of the coating.

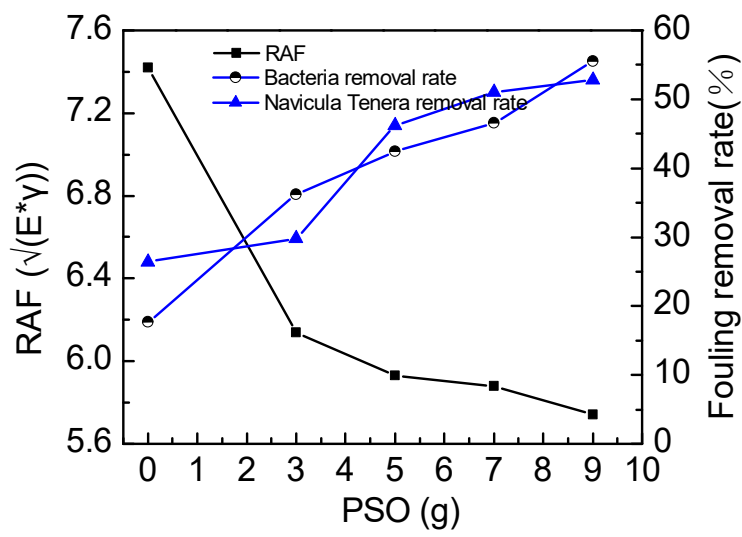

Figure 10. The influence of the addition amount of PSO on relative adhesion factor (RAF) and removal rate. 


\subsection{Effect of Water Contact Angle (WCA) and Elongation}

As shown in Figure 11a, at 800 rpm, the WCA and drag reduction rate gradually increase, as the addition amount of PSO increases. Spraying makes the surface of the coating have a certain surface roughness (Table 3). According to the research of Ming et al. [32], as the WCA increases, the coating with micro-nano structure will reduce the wettability and contact area between it and the fluid. Macroscopically, at 800-1400 rpm, the larger the contact angle was, the higher the drag reduction rate was, as shown in Figure 8a.

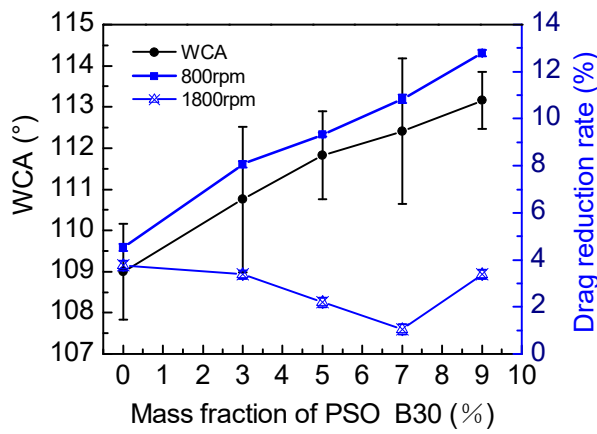

(a)

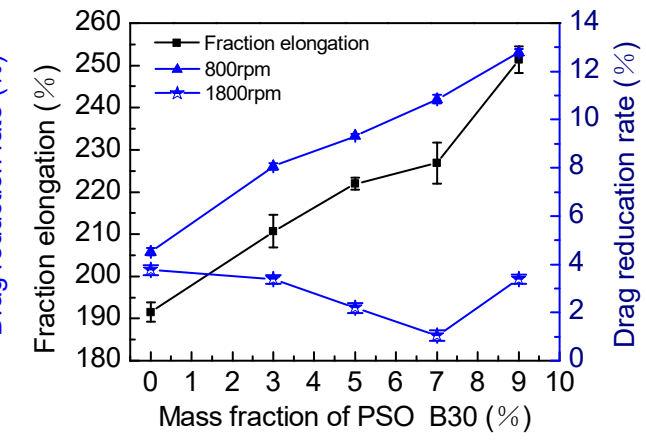

(b)

Figure 11. (a) The influence of the addition amount of PSO on WCA and drag reduction rate, (b) the influence of the addition amount of PSO on fraction elongation and drag reduction rate.

The higher the coating fraction elongation, the better flexibility. Studies have shown that a flexible hydrophobic coating is an ideal drag-reducing material [12]. Wu found that when the elongation reaches $83.3 \%$, drag reduction of the hydrophobic coating performs best [32]. Therefore, it can prove that increasing elongation will enhance the drag reduction effect of the coating.

When the speed reaches more than $1400 \mathrm{rpm}$, the seawater is in a turbulent state. As shown in Figure 11, at $1800 \mathrm{rpm}$, the water contact angle and elongation of the coating have no obvious influence on the drag reduction rate.

\section{Conclusions}

In this study, PSO was used to modify PDMS, and a series of silicone oil-modified silicone coatings were successfully manufactured to explore the effect of PSO addition amount and viscosity on the performance of silicone coating.

Author Contributions: Conceptualization, Q.Y., Z.Z., and Y.Q.; methodology, Q.Y., Z.Z., and Y.Q.; validation, Q.Y., Z.Z., and Y.Q.; formal analysis, Q.Y., Z.Z., and Y.Q.; investigation, Q.Y. and H.Z.; resources, Z.Z. and Y.Q.; data curation, Q.Y. and H.Z.; writing-original draft preparation, Q.Y. and Z.Z.; writing-review and editing, Q.Y., Z.Z., and Y.Q.; visualization, Q.Y.; supervision, Z.Z. and Y.Q.; project administration, Z.Z. and Y.Q.; funding acquisition, Z.Z. and Y.Q. All authors have read and agreed to the published version of the manuscript.

Funding: This research is supported by the National Science Foundation of China (51879021), Project of Equipment Pre-research Field Fund (61409220304) and Equipment Pre-research Sharing Technology Project (41404010306, 41423060314).

Conflicts of Interest: The authors declare no conflict of interest.

\section{References}

1. Liu, C.; Ma, C.; Xie, Q.; Zhang, G. Self-repairing silicone coatings for marine anti-biofouling. J. Mater. Chem. A 2017, 5, 15855-15861. [CrossRef]

2. Nassif, L.A.; Rioual, S.; Farah, W.; Fauchon, M.; Toueix, Y.; Hellio, C.; Abboud, M.; Lescop, B. Electrophoretic deposition of zinc alginate coatings on stainless steel for marine antifouling applications. J. Environ. Chem. Eng. 2020, 8, 104246. [CrossRef] 
3. Rossini, P.; Napolano, L.; Matteucci, G. Biotoxicity and life cycle assessment of two commercial antifouling coatings in marine systems. Chemosphere 2019, 237, 124475. [CrossRef] [PubMed]

4. Yang, W.J.; Neoh, K.-G.; Kang, E.-T.; Teo, S.L.-M.; Rittschof, D. Polymer brush coatings for combating marine biofouling. Prog. Polym. Sci. 2014, 39, 1017-1042. [CrossRef]

5. Zhou, E.; Li, H.-B.; Yang, C.; Wang, J.; Xu, D.; Zhang, D.; Gu, T. Accelerated corrosion of 2304 duplex stainless steel by marine Pseudomonas aeruginosa biofilm. Int. Biodeterior. Biodegrad. 2018, 127, 1-9. [CrossRef]

6. Sebastian, D.; Yao, C.-W.; Lian, I. Abrasion Resistance of Superhydrophobic Coatings on Aluminum Using $\mathrm{PDMS} / \mathrm{SiO}_{2}$. Coatings 2018, 8, 414. [CrossRef]

7. Rahimi, A.; Stafslien, S.J.; Vanderwal, L.; Finlay, J.A.; Clare, A.S.; Webster, D.C. Amphiphilic zwitterionic-PDMS-based surface-modifying additives to tune fouling-release of siloxane-polyurethane marine coatings. Prog. Org. Coat. 2020, 149, 105931. [CrossRef]

8. Yebra, D.M.; Kiil, S.; Dam-Johansen, K. Antifouling technology-Past, present and future steps towards efficient and environmentally friendly antifouling coatings. Prog. Org. Coat. 2004, 50, 75-104. [CrossRef]

9. Leonardi, A.K.; Ober, C.K. Polymer-Based Marine Antifouling and Fouling Release Surfaces: Strategies for Synthesis and Modification. Annu. Rev. Chem. Biomol. Eng. 2019, 10, 241-264. [CrossRef]

10. Krishnan, S.; Wang, N.; Ober, C.K.; Finlay, J.A.; Callow, M.E.; Callow, J.A.; Hexemer, A.; Sohn, K.E.; Kramer, E.J.; Fischer, D.A. Comparison of the fouling release properties of hydrophobic fluorinated and hydrophilic PEGylated block copolymer surfaces: Attachment strength of the diatom Navicula and the green alga Ulva. Biomacromolecules 2006, 7, 1449-1462. [CrossRef]

11. Li, S.; Liu, X.; Li, L.; Zhang, H.; Qiu, C. Drag-reductive and anti-corrosive superhydrophobic surface fabricated on aluminum with thin $\mathrm{PDMS} / \mathrm{SiO}_{2}$ coating. Mater. Res. Express 2019, 6, 1065a8. [CrossRef]

12. Wu, Y.; Shen, Y.; Tao, J.; He, Z.; Xie, Y.; Chen, H.; Jin, M.; Hou, W. Facile spraying fabrication of highly flexible and mechanically robust superhydrophobic $\mathrm{F}_{-} \mathrm{SiO}_{2} @ \mathrm{PDMS}$ coatings for self-cleaning and drag-reduction applications. New J. Chem. 2018, 42, 18208-18216. [CrossRef]

13. Tian, S.; Jiang, D.; Pu, J.; Sun, X.; Li, Z.; Wu, B.; Zheng, W.; Liu, W.; Liu, Z. A new hybrid silicone-based antifouling coating with nanocomposite hydrogel for durable antifouling properties. Chem. Eng. J. 2019, 370, 1-9. [CrossRef]

14. Liu, Y.; Gu, H.; Jia, Y.; Liu, J.; Zhang, H.; Wang, R.; Zhang, B.; Zhang, H.; Zhang, Q. Design and preparation of biomimetic polydimethylsiloxane (PDMS) films with superhydrophobic, self-healing and drag reduction properties via replication of shark skin and SI-ATRP. Chem. Eng. J. 2019, 356, 318-328. [CrossRef]

15. Yang, M.; Sun, Y.; Chen, G.; Wang, G.; Lin, S.; Sun, Z. Preparation of a self-healing silicone coating for inhibiting adhesion of benthic diatoms. Mater. Lett. 2020, 268, 127496. [CrossRef]

16. Nasrollahi, N.; Vatanpour, V.; Aber, S.; Mahmoodi, N.M. Preparation and characterization of a novel polyethersulfone (PES) ultrafiltration membrane modified with a $\mathrm{CuO} / \mathrm{ZnO}$ nanocomposite to improve permeability and antifouling properties. Sep. Purif. Technol. 2018, 192, 369-382. [CrossRef]

17. Manna, U.; Raman, N.; Welsh, M.A.; Zayas-Gonzalez, Y.M.; Blackwell, H.E.; Palecek, S.P.; Lynn, D.M. Slippery Liquid-Infused Porous Surfaces that Prevent Microbial Surface Fouling and Kill Non-Adherent Pathogens in Surrounding Media: A Controlled Release Approach. Adv. Funct. Mater. 2016, 26, 3599-3611. [CrossRef]

18. Amini, S.; Kolle, S.; Petrone, L.; Ahanotu, O.; Sunny, S.; Sutanto, C.N.; Hoon, S.; Cohen, L.; Weaver, J.C.; Zhang, C.T.; et al. Preventing mussel adhesion using lubricant-infused materials. Science 2017, 357, 668-673. [CrossRef]

19. Cui, W.; Pakkanen, T.A. Icephobic performance of one-step silicone-oil-infused slippery coatings: Effects of surface energy, oil and nanoparticle contents. J. Colloid Interface Sci. 2020, 558, 251-258. [CrossRef]

20. Ba, M.; Zhang, Z.; Qi, Y. Fouling Release Coatings Based on Polydimethylsiloxane with the Incorporation of Phenylmethylsilicone Oil. Coatings 2018, 8, 153. [CrossRef]

21. Galhenage, T.P.; Hoffman, D.; Silbert, S.D.; Stafslien, S.J.; Daniels, J.; Miljkovic, T.; Finlay, J.A.; Franco, S.C.; Clare, A.S.; Nedved, B.T.; et al. Fouling-Release Performance of Silicone Oil-Modified Siloxane-Polyurethane Coatings. ACS Appl. Mater. Interfaces 2016, 8, 29025-29036. [CrossRef]

22. Liu, F.J.; Qi, Y.H.; Zhang, Z.P. The effect of curing agent and silane coupling agent on the properties of silicone coatings. China Surf. Eng. 2014, 27, 114-119. (In Chinese)

23. Oliver, J.F.; Mason, S.G. Liquid spreading on rough metal surfaces. J. Mater. Sci. 1980, 15, 431-437. [CrossRef] 
24. Díaz-Tena, E.; Rojo, N.; Gurtubay, L.; Rodríguez-Ezquerro, A.; López de Lacalle, L.N.; Oyanguren, I.; Barbero, F.; Elías, A. Biomachining: Preservation of Acidithiobacillus ferrooxidans and treatment of the liquid residue. Eng. Life Sci. 2017, 17, 382-391. [CrossRef] [PubMed]

25. Liu, S.; Zhang, Z.P.; Qi, Y.H. Effect of Emulsifier on the Structure and Properties of Waterborne Silicone Antifouling Coating. Coatings 2020, 10, 168. [CrossRef]

26. Liu, H.; Zhang, Z.P.; Qi, Y.H.; Liu, S.H.; Lin, J.G.; Fang, K.; Zhang, Z.W. Experimental methods for evaluation of benthic diatom adhesion on the surface of non-toxic antifouling coatings. Mar. Environ. Sci. 2006, 25, 89-92. (In Chinese)

27. GB/T 7791-2014. Test Method for Performance of Reducing Frictional Resistance of Antifouling Coatings; The Standardization Administration of China: Beijing, China, 2014. (In Chinese)

28. Lai, G.Q.; Xin, S.M. Synthetic Process and Application of Organosilicon; Chemical Industry Press: Beijing, China, 2010; p. 420. (In Chinese)

29. Selim, M.; Shenashen, M.; El-Safty, S.A.; Higazy, S.; Isago, H.; Elmarakbi, A. Recent progress in marine foul-release polymeric nanocomposite coatings. Prog. Mater. Sci. 2017, 87, 1-32. [CrossRef]

30. Sun, Y.; Guo, S.; Walker, G.; Kavanagh, C.J.; Swain, G. Surface elastic modulus of barnacle adhesive and release characteristics from silicone surfaces. Biofouling 2004, 20, 279-289. [CrossRef]

31. Callow, J.A.; Callow, M.E. Trends in the development of environmentally friendly fouling-resistant marine coatings. Nat. Commun. 2011, 2, 244. [CrossRef]

32. Zhou, M.; Li, J.; Wu, C.; Zhou, X.; Cai, L. Fluid drag reduction on superhydrophobic surfaces coated with carbon nanotube forests (CNTs). Soft Matter 2011, 7, 4391-4396. [CrossRef]

33. Martinelli, E.; Guazzelli, E.; Bartoli, C.; Gazzarri, M.; Chiellini, F.; Galli, G.; E Callow, M.; Callow, J.A.; Finlay, J.A.; Hill, S. Amphiphilic pentablock copolymers and their blends with PDMS for antibiofouling coatings. J. Polym. Sci. Part A Polym. Chem. 2015, 53, 1213-1225. [CrossRef]

34. Brady, R.F.; Singer, I.L. Mechanical factors favoring release from fouling release coatings. Biofouling 2000, 15, 73-81. [CrossRef] [PubMed]

Publisher's Note: MDPI stays neutral with regard to jurisdictional claims in published maps and institutional affiliations.

(C) 2020 by the authors. Licensee MDPI, Basel, Switzerland. This article is an open access article distributed under the terms and conditions of the Creative Commons Attribution (CC BY) license (http://creativecommons.org/licenses/by/4.0/). 